\title{
Formação e desenvolvimento profissional de professores: elementos norteadores da ação docente na perspectiva crítico-reflexiva
}

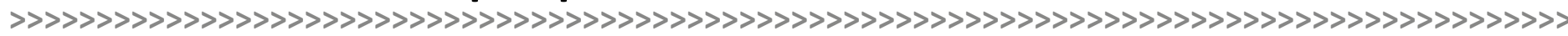

\author{
Eunice Andrade de Oliveira Menezes* \\ Silvia Maria Nóbrega-Therrien** \\ Cicera Sineide Dantas Rodrigues ${ }^{* * *}$ \\ Giovana Maria Belém Falcão***
}

\section{Resumo:}

Este estudo busca realçar a importância de uma formação docente que contemple o desenvolvimento do pensamento reflexivo do professor, em nível crítico, de forma a destacá-lo como um elemento essencial à prática docente, pois defende a ideia de que a reflexão pode favorecer novos modos de atuação do professor no processo de formação contínua, uma vez que ela orienta a ação docente quanto à exigência que há no trajeto da profissão para o desenvolvimento de habilidades, tanto de cunho teórico quanto prático. Como referencial teórico principal, o presente estudo traz proposições de Dewey (1959), Schön (2000), Freire (2011) e Nóvoa (2007; 2009) nos pormenores da formação docente e do desenvolvimento profissional, discutindo, para tal, a relevância dos estudos da reflexividade.

\section{Palavras-chave:}

Reflexão. Pensamento reflexivo. Formação docente. Desenvolvimento profissional.

\begin{abstract}
:
This paper sought to highlight the importance of a teaching formation that engulfs, at critical level, the development of teacher's reflexive thinking in order to enhance it as an essential element to the teaching practice, so it supports the idea that reflection may favor new ways of teacher's acting in the continued fornation, once that guides the teaching action for the requirement that is in the professional path for the development of skills, both theoretical and practical nature. As the main theoretical background, this study brings propositions from Dewey (1959), Schön (2000), Freire (2011), and Nóvoa (2007; 2009) in the details of teaching formation and professional development, for which the reflexivity study relevance is discussed.
\end{abstract}

\section{Keywords:}

Reflection. Reflexive thinking. Teaching formation. Professional development.

\section{Introdução}

A crescente complexidade das questões sociais deveria contribuir para que a profissão docente superasse fragilidades que evidenciam tanto o seu desprestígio quanto a sua proletarização. Diferente disso, se tem verificado por parte dos professores a mani-

\footnotetext{
* > Doutoranda em Educação na Universidade Estadual do Ceará - UECE. E-mail: euniceagosto@yahoo.com.br

** > Professora Doutora do Programa de Pós-Graduação em Educação da Universidade Estadual do Ceará - UECE. E-mail: silnth@terra.com.br

*** > Professora assistente da Universidade Regional do Cariri - URCA e doutoranda em educação pela Universidade Estadual do Ceará-UECE
}

**** > Doutoranda em Educação na Universidade Estadual do Ceará - UECE. E-mail: giovana.belem@yahoo.com.br 
festação de sentimentos de segmentação e de isolamento cada vez mais progressivos que incidem negativamente na prática pedagógica. Isso é algo que se faz notório em diferentes momentos da profissão: nas rotinas da sala de aula, nas reuniões de planejamento, na participação em determinados eventos que, contraditoriamente, objetivam a formação docente, por exemplo.

Diante dessa realidade, surge o ditame de resistência e de oposição do professorado à formação docente calcada no paradigma da racionalidade técnica, modelo que se erige da concepção positivista do conhecimento. Em lugar desta, urge um modelo formativo que se firme na perspectiva que contemple o desenvolvimento do pensamento reflexivo do professor, em nível crítico, perspectiva essa que, como sugere Freire (2011), promove a curiosidade ingênua em curiosidade epistemológica diante dos problemas da prática docente.

Apesar de Paulo Freire não ser habitualmente associado ao estudo da reflexão na prática educativa, o referido autor foi um dos estudiosos que mais se ocupou dessa temática, tomando-a como um elemento essencial à prática docente. Nesse pormenor, Freire (2011) aborda o conceito de reflexão sustentando sua base na perspectiva dialética da realidade. No enfoque freireano, é a unidade dialética que origina um agir e um pensar críticos sobre a realidade para transformá-la. Para esse autor, reflexão é o movimento efetivado entre o fazer e o pensar e vice-versa, ou seja, a ação se fará autêntica práxis, se o saber dela resultante se fizer objeto da reflexão crítica e transformadora.

Dessa forma, entende-se que o professor preparado para lidar com a complexidade de uma sociedade plural e desigual, e um sujeito com diversas habilidades que se materializam na fusão do conhecimento teórico e prático, não se encontram prontos para solucionar conflitos, tal como um herói de contos de fadas. Mas, um profissional que se forma dia após dia, em presença das lutas, das frustrações, dos temores, do improvável, das incertezas e de outras tantas situações inerentes ao exercício da docência. Sendo assim, diante de tantos desafios enfrentados pelo professor, a formação docente dá sinais de que, cada vez mais, se reafirma como um contributo para o seu desenvolvimento profissional, apesar de ela não ser a única via desse desenvolvimento, assunto que se discutirá na segunda sessão deste estudo.

Diante do exposto, o presente texto objetiva refletir sobre a importância de uma formação docente que contemple o desenvolvimento do pensamento reflexivo do professor, acreditando que, no processo de formação contínua à reflexão, pode favorecer novos modos de atuação do professor, uma vez que ela contribui para reorientar a sua ação docente. No entanto, o pretenso patamar de "professor reflexivo" pode limitar-se apenas a um discurso teórico ou mesmo a tornar-se mais uma imposição, mais um devir do professor, sobretudo, se analisadas as reais condições que esse profissional tem para refletir.

Para subsidiar a discussão, apresenta-se a seguir o conceito de "professor reflexivo" que advém das ideias de Dewey (1959) Schön (2000). No tópico seguinte, propõe-se uma reflexão sobre os construtos “formação docente" e "desenvolvimento profissional” e, em seguida, traz-se à tona alguns questionamentos sobre as disposições e facetas que caracterizam o "bom professor". Por último, enseja-se algumas conclusões.

\section{As concepções de matriz schönianas que desembocaram no conceito "professor reflexivo"}

A "Epistemologia da prática reflexivo" ou o conceito de "professor reflexivo" surgiu de um movimento de reformas educacionais, em âmbito mundial, no final da década de 1980 e no princípio da década de 1990. Como abordagem teórico-metodológica para a formação de professores, essa perspectiva foi proposta por pesquisadores que debatiam a formação inicial e contínua de professores em diversos países. Autores como Donald Schön 
e Kenneth Zeichner, dos Estados Unidos, António Nóvoa e Isabel Alarcão, de Portugal, Gimeno Sacristán e Angel Peréz Gomez, da Espanha, e os brasileiros, Selma Garrido e José Carlos Libâneo, dentre outros, têm seus nomes associados à difusão dessa abordagem. Contudo, é John Dewey o principal expoente dessa perspectiva teórico-metodológica, sendo considerado como o precursor do conceito de pensamento reflexivo, que tanto tem influenciado o percurso de formação docente na educação contemporânea.

Para Dewey (1959), autor norte-americano, o pensar reflexivo tanto se distingue do pensamento confuso, quanto da crença sobre algo já estabelecido, isento de sustentação em fatos ou argumentos racionais. Para ele, a reflexão principia em um estado de dúvida que desencadeia a investigação com o intuito de encontrar recursos suficientes para elucidar a indagação original. Esse é um conceito mais amplo do que a mera capacidade de meditar sobre algo, uma vez que o pensar reflexivo, para Dewey:

[...] diferentemente das outras operações a que se dá o nome de pensamento, abrange: (1) estado de dúvida, hesitação, perplexidade, dificuldade mental o qual origina o ato de pensar; e (2) um ato de pesquisa, procura, inquirição, para encontrar material que resolva a dúvida, assente e esclareça a perplexidade. (DEWEY, 1959, p. 22).

É oportuno lembrar que as propostas acerca do professor reflexivo aportaram inicialmente nos Estados Unidos, principalmente, por meio da obra de Donald Schön The Reflective Practitioner, lançada em 1983, obra esta que sofreu influência direta das ideias de Dewey acerca do pensamento reflexivo e suas contribuições para a prática docente. Dessa forma, as proposições de Schön tornaram-se um referencial para os programas de formação de professores que anunciam que os professores edificam sua prática docente baseados na ação.

Sendo assim, denunciando o modelo da racionalidade técnica como incapaz de tratar tudo que é imprevisível na atuação profissional, e baseando-se em Dewey, Schön investigou a forma como um ensino prático-reflexivo poderia causar mudanças e quais as implicações disso na escola. Importa destacar que este autor utiliza o termo professional artistry para assinalar as competências que o professor revela em situações de conflito. Schön (2000) defende que a reflexão surge associada ao modo como se convive com os problemas da prática, diante da incerteza, o que resulta em novos contornos para esses problemas, convergindo para a descoberta de novas maneiras de solucioná-los.

Dentro dos estudos sobre reflexão, é sabido que as contribuições de Dewey (1959) e Schön (2000) realçam a relevância da experiência na prática no processo de ensino-aprendizagem e chamam atenção para a importância da pesquisa-ação e da observação e auto-observação como atividades que possibilitam ao professor um fazer docente mais lúcido, mais consciente e que, consequentemente, concorra para a transformação social.

Nesse cenário, a ideia de profissional reflexivo desenvolvida por Schön (2000) propõe uma nova prática formativa que passa pela valorização da experiência e da reflexão na experiência, visto que o autor ${ }^{1}$ trata da formação de professores situada na investigação do trabalho em sala de aula e na escola, ao buscar suscitar nesses profissionais a capacidade de refletir sobre a própria prática com uma atitude que contribua para tornar explícitos seus saberes tácitos, provenientes de sua experiência.

Ademais, o autor indica o reconhecimento da existência dos saberes tácitos como o primeiro passo para que o professor possa levantar questionamentos sobre as teorias que norteiam seu trabalho docente, bem como sobre as estratégias de que se utiliza na prática, o que lhe possibilita a transformação dos seus modos de atuação. Para Schön (2000), o profissional reflexivo, tem uma nova proposta de epistemologia da prática que foi concebida para "lidar mais facilmente com a questão do conhecimento profissional." (SCHÖN, 2000, p. 7).
$1>$ Considera-se importante destacar que a obra de Donald Schön entrou na área da educação após vários estudos e atividades que o autor realizou, na década de 1970, relacionadas às reformas curriculares nos cursos de formação profissional do MIT (Instituto de Tecnologia de Massachusetts, EUA), principalmente na Escola de Arquitetura dessa instituição. 
Na centralidade das proposições de Donald Schön para a formação profissional, encontra-se a distinção entre o conhecimento tácito, o qual o autor também denomina "conhecimento-na-ação", e o conhecimento escolar. Schön (2000) diferencia o que ele designa de "conhecer-na-ação" e o que ele chama "reflexão-na-ação". O primeiro, marcado pela espontaneidade, pelo que é rotineiro, é, por isso, tácito. O segundo, oriundo de resultados inesperados e da imprevisibilidade produzida pela ação, não é tão espontâneo quanto o "conhecer-na-ação". A reflexão-na-ação teria, para Schön, então, "uma função crítica, que questiona a estrutura de pressupostos do conhecer-na-ação” (SCHÖN, 2000, p. 33).

Além do mais, ao tratar de processos reflexivos que permeiam a prática profissional, Schön (2000) assegura que a reflexão é enfocada nessa prática interativamente, de formas distintas: a reflexão-na-ação (reflection-in-action), a reflexão-sobre-a-ação (reflection-on-action) e a reflexão-sobre-a-reflexão-na-ação (reflection-on-reflection-in-action). Veja-se que o autor estabelece algumas distinções entre esses processos:

\begin{abstract}
Assim como o conhecer-na-ação, a reflexão na ação é um dos processos que podemos desenvolver sem que precisemos dizer o que estamos fazendo. Improvisadores habilidosos ficam, muitas vezes, sem palavras ou dão descrições inadequadas quando se lhes pergunta o que fazem. É claro que, sermos capazes de refletir-na-ação é diferente de sermos capazes de refletir sobre nossa reflexão-na-ação, de modo a produzir uma boa descrição verbal dela. E é ainda diferente de sermos capazes de refletir sobre a descrição resultante. Contudo, nossa reflexão sobre nossa reflexão-na-ação passada pode conformar indiretamente nossa ação futura. (SCHÖN, 2000, p. 35-36).
\end{abstract}

Com o exposto, depreende-se que a reflexão-na-ação emerge diante de situações inesperadas e que a reflexão-sobre-a-ação, por sua vez, surge quando a ação é concretizada, algo que desencadeia, então, uma análise sobre o que ocorreu e também sobre a forma como a ação foi realizada. Dessa forma, as descrições do professor sobre sua ação têm origem na reflexão. No caso de a descrição ocorrer simultaneamente à ação, sucede a reflexão-na-ação; se a descrição ocorrer posteriormente à ação, então, há exemplo de reflexão-sobre-a-ação. Por último, a reflexão-sobre-a-reflexão-na-ação ajuda o professor a construir sua própria forma de lidar com o conhecimento e com a experiência.

Portanto, para Schön (2000), esses processos reflexivos, manifestam-se diante do enfrentamento das situações problemáticas do dia a dia da prática docente, situações estas caracterizadas pela necessidade de decisões imediatas diante da imprevisibilidade inerente ao contexto da sala de aula. Em outras palavras, Contreras (2012), expõe que a prática calcada em atitudes reflexivas concorre para romper "[...] a tradicional dicotomia entre a pesquisa, por um lado, e a prática entendida como aplicação dos produtos da primeira, por outro". (CONTRERAS, 2012, p. 123).

Dessa forma, crê-se que as concepções de matriz schonianas foram rapidamente disseminadas e ampliadas em vários países porque questionaram a formação docente enraizada em uma perspectiva de racionalidade técnica, muito embora, entenda-se que a reflexão em Schön seja dirigida a problemas individuais e imediatos da prática profissional. Contreras (2012) acredita que "a obra de Schön permite recuperar [...] uma concepção da prática que, sob a racionalidade técnica, ficava excluída de toda compreensão possível e marginalizada em seu valor ao não ser produto da aplicação do conhecimento técnico-científico". (CONTRERAS, 2012, p. 125-126).

Não obstante, reconheça-se a grande contribuição de Donald Schön para a formação docente ao formular sua "epistemologia do profissional reflexivo", entende-se, ao mesmo tempo, que sua obra apresenta mais um modelo alicerçado em estudos de casos concretos, próprios da vida escolar, do que um projeto que tome a reflexão como possibilidade de transformação de vários aspectos da prática profissional, como a reflexão sobre o próprio 
percurso formativo do professor, sua identidade enquanto profissional da educação, seus saberes docentes, a pesquisa sobre sua prática etc.

Sendo assim, concorda-se que a epistemologia da prática proposta por Schön resultou em grandes avanços no que tange à crítica de concepções positivistas que sustentavam (e ainda sustentam) muitas inciativas para a formação docente, porém, o que se defende neste estudo é uma abordagem de formação de professores que não se reduza à análise de situações próprias à sala de aula, mas que impulsione o professor a refletir em várias outras situações, contemplando aspectos sociais para além da prática escolar.

Entretanto, ao se discutir a proposição schoniana de uma epistemologia da prática, é mister problematizar algumas questões atinentes à formação docente, por exemplo: Formação é o elemento definidor da promoção do desenvolvimento profissional dos professores? Qual o papel dos professores na elaboração de políticas que definirão suas próprias formas de atuação docente? Que lugar tem se conferido a esses profissionais nas deliberações que implicam em seu próprio processo de formação? Tais questões, que se relacionam de forma estreita com o pensamento reflexivo crítico, ocuparão as discussões da próxima sessão deste estudo.

\section{Formação e desenvolvimento profissional docente: conceitos análogos?}

Apesar de a formação dos professores ser apresentada como elemento impulsionador e realizador das reformas educativas e também como componente que cria condições para a transformação da escola, da universidade e da sociedade, de modo geral, torna-se evidente que apenas a formação não é suficiente para a promoção do desenvolvimento profissional dos professores.

Nesse contexto, o processo de formação se traduz como uma importante dimensão do desenvolvimento profissional docente, porém, se reconhece que as políticas institucionalizadas de desenvolvimento profissional não são menos relevantes que esse processo.

Não obstante, a formação e o desenvolvimento profissional serem fenômenos que vêm crescendo nos debates sobre a educação nacional desde a década de 1980, ambos, por vezes, têm sofrido entendimentos e discussões que os qualificam como sinônimos. Imbernón, no entanto, alerta para o fato de que desenvolvimento profissional é um conceito bem mais amplo do que o conceito de formação docente, ainda que esta integre o desenvolvimento profissional. A esse respeito o autor diz:

\begin{abstract}
Si aceptamos tal similitude estamos considerando El desarrollo professional del professorado de um modo muy restrictivo, sería como afirmar que la formación es la única via de desarrollo profesional Del profesorado. Desde nuestro contexto no podemos asseverar que El desarrollo profesional Del profesorado sea debido unicamente al desarrollo pedagógico, al conocimiento y comprensión de si mismo, al desarrolho cognitivo o al desarrollo teórico, sino a todo eso y a la vez em marcado, es decir, integrado em uma situación laboral que facilita o dificulta el desarrollo de uma carrera docente. (IMBERNÓN, 1999, p. 59-60). ${ }^{2}$
\end{abstract}

De fato, entra-se em acordo com a declaração de Imbernón, haja vista que o conceito de desenvolvimento profissional pressupõe a ideia de crescimento, de expansão das possibilidades de ação dos professores. Para tanto, há de se refletir sobre duas dimensões que se apresentam como inseparáveis na prática docente: a formação do professor e as condições concretas em que ele atua. Concebendo-se a formação como um dos componentes do desenvolvimento profissional, entender-se-ão um conjunto de questões que historicamente têm permeado a profissão docente: salário, jornada de trabalho, estatuto
$2>$ Se aceitarmos tal similitude estamos considerando o desenvolvimento profissional do professorado de modo muito restritivo; seria como afirmar que a formação é a única via de desenvolvimento profissional dos professores. Em nosso contexto não podemos asseverar que o desenvolvimento profissional dos professores é devido unicamente ao desenvolvimento pedagógico, ao conhecimento e à compreensão de si mesmo, ao desenvolvimento cognitivo ou ao desenvolvimento teórico, mas a tudo isso e, ao mesmo tempo, marcado, quer dizer, integrado em uma situação de trabalho que facilita ou dificulta o desenvolvimento de uma carreira docente. (Tradução nossa). 
de profissão (ou perda deste), carreira, condições objetivas de trabalho, currículo, gestão etc. A esse respeito observa-se o conceito de desenvolvimento profissional docente pelo prisma de Garcia:

[...] mais do que aos termos aperfeiçoamento, reciclagem, formação em serviço, formação permanente, convém prestar uma atenção especial ao conceito de desenvolvimento profissional dos professores, por ser aquele que melhor se adapta à concepção actual do professor como profissional de ensino. A noção de desenvolvimento tem uma conotação de evolução e de continuidade que nos parece superior à tradicional justaposição entre formação inicial e aperfeiçoamento dos professores. (GARCIA, 2007, p. 55).

Torna-se perceptível, portanto, o caráter processual e sequencial que esse autor acentua no construto "desenvolvimento profissional", o que o leva a compreendê-lo como algo que está para além da noção de formação inicial e de aperfeiçoamento.

Fortalecendo sua argumentação sobre a necessidade de se lançar atenção especial sobre a formação e sobre o desenvolvimento profissional dos professores, em outra obra Garcia (1999) discorre sobre as concepções diferenciadas de alguns teóricos, concepções estas que envolvem desenvolvimento pedagógico, conhecimento e compreensão do professor sobre sua própria imagem, seus desenvolvimentos cognitivo, teórico, profissional e da carreira. Garcia, no entanto, se posiciona quanto à formação e o desenvolvimento profissional docente, afastando a possibilidade de dualismo entre esses construtos:

Já afirmámos que um dos elementos positivos que encontrámos na utilização do conceito desenvolvimento profissional reside no facto de pretender superar a concepção individualista e celular das práticas habituais de formação permanente. Quer isso dizer que o desenvolvimento do professor não ocorre no vazio, mas inserido num contexto mais vasto de desenvolvimento organizacional e curricular. (GARCIA, 1999, p. 139, grifos do autor).

Contudo, a prática comum nos mostra que as atividades ditas formativas dos docentes são geralmente descontextualizadas e centradas na figura de "especialistas" que acabam por negar a condição dos professores como produtores de conhecimento. Essas abordagens "formativas" desconsideram os referidos profissionais como sujeitos aptos a conduzirem sua trilha profissional sem terem que seguir servis, ouvindo e acatando as ordens de forças exteriores à realidade escolar.

Para se tratar de políticas de desenvolvimento profissional docente, entretanto, é necessário que estas sejam integradas a uma formação com profissionalização, visto que a íntima relação entre desenvolvimento profissional e a formação docente traduz o elo entre a formação do professor, a profissão e a construção da sua identidade de educador. Essa dinâmica se realiza na medida em que contribui para a função social da escola, ou seja, para a instrumentalização de um ensino no qual se possa garantir a educação para a vida e a universalização da educação.

Com essa lógica, crê-se que ao professor caiba a tarefa de um desenvolvimento profissional em concordância com o seu ritmo de trabalho, de maneira que a dimensão pedagógica se concretize, pois, do contrário, sua função social, que é a de contribuir para uma educação emancipatória, não se cumprirá.

Nessa mesma direção, ainda Garcia (1999), ao tratar de formação inicial, defende a presença de níveis e componentes do conhecimento profissional docente:

a. o conhecimento psicopedagógico é aquele relacionado com o ensino e com os seus princípios gerais, com a aprendizagem e com os alunos. Esse tipo de conhecimento é também determinado pelo autor como "conhecimento profissional"; 
b. o conhecimento do conteúdo é pertinente à matéria que os professores ensinam e que lhes permitem ensinar algo, pelo fato de estarem preparados para tal. Em contrapartida, a falta de conhecimento do professor pode afetar o nível de aprendizagem dos alunos, o que concorre para que estes tenham seu desenvolvimento comprometido;

c. o conhecimento didático do conteúdo é considerado por esse autor como elemento central do conhecimento do professor, pois se relaciona à combinação entre o conhecimento da matéria e o conhecimento pedagógico e didático;

d. o conhecimento, por fim, do contexto é componente que diz respeito ao local onde se ensina, bem como a quem se ensina. Nesse pormenor, Garcia expõe que os "professores têm de adaptar o seu conhecimento geral da matéria às condições particulares da escola e dos alunos que a frequentam" (GARCIA, 1999, p. 91).

Dessa forma, esses conhecimentos abarcam dimensões fundamentais para a competência profissional do docente que está em um processo contínuo de desenvolvimento profissional, visto que os conhecimentos que os professores detêm estão relacionados à realidade em que vivem e atuam. Sendo assim, aprendendo e ensinando em um contexto situado, eles precisam estar se formando com vistas ao domínio de competências que extrapolem a transposição da matéria, que os motivem a se comprometer com um projeto educativo que abarque atitudes de respeito às questões de etnia, de gênero, de ordem (religiosa, social, econômica etc.).

Em associação às proposições de Garcia (1999; 2007), quando trata de necessidades formativas e de conhecimento profissional, Nóvoa (2009) defende especificamente um imperativo para o professorado: o de uma formação de professores construída dentro da profissão. Desse modo, o autor discorre sobre cinco facetas da problemática "formação docente", a saber: prática, profissão, pessoa, partilha, público. Em sessão subsequente, tem-se como tarefa discutir essas facetas, anunciando antes, mesmo que brevemente, uma crítica de Nóvoa (2007) sobre as exigências que têm definido o "bom professor", sob a lente da lógica positivista. É o que se discutirá adiante.

\section{O "bom professor": que disposições e facetas o caracterizam?}

O termo "disposições", usado por Nóvoa (2009) em lugar do conceito de "competências" sofre sua crítica pelo fato de este conceito ter tomado uma configuração que limita o "bom professor" a uma lista interminável de que fazeres, na maioria das vezes, impostos por "ordens superiores".

A escolha do termo "disposições" evidencia a necessária análise reflexiva sobre a quase imposição do conceito "competências" que surgiu na década de 1990, conceito este que, no decorrer dos anos, continua preso às suas origens de cariz técnico e instrumental. Nos termos de Nóvoa, a eleição pelo termo “disposição", vinculado ao trabalho docente pretende

[...] romper com um debate sobre as competências que me parece saturado. Adoto um conceito mais "liquido" e menos "solido", que pretende olhar preferencialmente para a ligação entre as dimensões pessoais e profissionais na produção identitária dos professores. (NÓVOA, 2009, p. 23).

Assim, para Nóvoa (2009), algumas disposições são necessárias para fortalecer o ofício de professor na contemporaneidade. Tais disposições ${ }^{3}$ envolvem:

a. O conhecimento: apontado pelo autor como essencial para a construção de práticas docentes que conduzam os alunos à aprendizagem, bem como a defesa de que o
3 > A demarcação que se utilizou dessas disposições propostas por Nóvoa, assinaladas por letras, não são usadas pelo autor em seu escrito. Trata-se de opção das autoras deste estudo e tem unicamente a intenção de apresentar uma organização textual que contribua para o entendimento desta discussão. 
professor deva conhecer muito bem aquilo que ensina. Entende-se dessa disposição que seja basilar para a competência profissional do docente que está em processo contínuo de desenvolvimento profissional, pois os conhecimentos que os professores detêm estão relacionados à realidade em que vivem e atuam.

b. A cultura profissional: para Nóvoa, a cultura profissional implica a integração dos professores na profissão docente, de modo a aprender com os colegas mais experientes. Essa aprendizagem, defende-se, inclui a reflexão sobre o trabalho, que, por sua vez, impele os docentes ao aperfeiçoamento da sua prática, o que pode contribuir para seu desenvolvimento profissional.

c. O tato pedagógico: reflete a capacidade de relação e de comunicação necessárias ao ato de educar. No ensino, as dimensões profissionais cruzam-se sempre, de maneira inevitável, com as dimensões pessoais. Por isso, é tão necessário que o professor tenha o respeito e a boa comunicação como ferramentais em suas relações com os alunos, com suas famílias e também com seus pares.

d. O trabalho em equipe: nas palavras de Nóvoa (2009, p. 31), “os novos modos de profissionalidade docente implicam um reforço das dimensões coletivas e colaborativas do trabalho em equipe, da intervenção conjunta nos projetos educativos de escola". Por isso, o "trabalho em equipe" traz a necessidade do exercício profissional organizado em torno de "comunidades de prática" (idem) no interior de cada instituição escolar.

e. Por fim, ao defender o compromisso social como uma importante disposição que deve caracterizar o trabalho docente, Nóvoa recomenda o papel dos valores, da inclusão social e da diversidade cultural no ser e fazer-se professor. Intervir no espaço público da educação, para o autor, "faz parte do ethos profissional docente" (NÓVOA, 2009, p. 31).

Sob o prisma das autoras deste estudo, inegavelmente, o compromisso social diz da capacidade reflexiva e da ontologia do ser professor, haja vista que, conforme nos assinala Freire "se nos interessa analisar o compromisso do profissional, teremos que reconhecer que ele, antes de ser profissional, é homem. Deve ser comprometido por si só" (FREIRE, 1979, p. 21)

Neste sentido, Nóvoa (2009) e Freire (2011) fazem uma relação relevante dos aspectos profissionais, pessoais e sociais inseridos na formação docente, mostrando de certa forma que a experiência e a práxis pedagógica são fundamentais para o processo de ensino/aprendizagem, não só do aluno que aprende, como do professor que ensina. Por consequência, o professor se forma, formando.

Notadamente, as disposições as quais se discutiu há pouco estabelecem relação íntima com as facetas anunciadas no final da sessão anterior, as quais retoma-se agora: prática, profissão, pessoa, partilha, público. Tais facetas, para Nóvoa (2009), contribuem para elaborar um conhecimento pessoal no interior do conhecimento profissional e para apreender o sentido de uma profissão que não se reduz a uma matriz técnica ou científica.

A componente prática a que Nóvoa se refere assume papel central na aprendizagem dos alunos e no estudo de casos concretos, sendo guiada pelo trabalho da instituição, seja ela de educação básica ou de ensino superior. Conforme Nóvoa (2009), essa componente pode contribuir para uma reflexão que permita transformar a prática em conhecimento, superando, assim, uma concepção de formação de professores mais dominada no trabalho docente por referências externas do que por referências internas.

Nóvoa (2009) ainda defende que a profissão docente deva tomar como base uma cultura profissional na qual os professores mais experientes tenham um papel central na formação dos mais jovens. Essa compreensão colaborativa do ensinar e do aprender a profissão, conforme compreende-se, pode contribuir para superar/enfrentar uma série de definições influenciadas por decisões externas que demarcam o contexto da formação de professores e os critérios sobre os desempenhos profissionais, tanto no Brasil como em toda a América Latina. Tais demarcações tendem a assumir um espaço que deveria ser 
da responsabilidade dos professores mais experientes, sendo, então, 'propostas' por uma série de especialistas e de entidades de avaliação e de validação de aspectos relevantes da profissão docente.

Outra faceta da problemática da formação docente mencionada por Nóvoa (2009) é a atenção que deve ser dedicada às dimensões pessoais da profissão docente, que o autor denomina componente-pessoa. Para o autor, embora muito mais no plano do discurso, uma máxima tem se sustentado ao longo das quatro últimas décadas: que professor é pessoa, e por isso não pode dissociar a dimensão pessoal da profissional. Esse pensamento ratifica a importância de motivar os futuros professores, e nos primeiros anos de exercício profissional, às práticas de autoformação, nas quais eles se utilizem de estratégias que contribuam para uma reflexão que ocorra na e sobre $a$ ação (SCHÖN, 2000, p. 34), como as narrativas da própria história de vida.

A formação de um tecido profissional enriquecido é expressa por Nóvoa (2009), como integradora da cultura docente, valendo-se de modos coletivos de produção e de regulação do trabalho, ou seja, da partilha. Entende-se que essa partilha se faz rica por objetivar transformar a experiência coletiva em conhecimento profissional, bem como por conectar a formação de professores ao desenvolvimento de projetos educativos nas escolas, nas universidades e nas demais instituições de ensino. Conforme Nóvoa, esse objetivo só pode se concretizar, se estiver voltado para a construção de programas de formação coerentes com o diálogo profissional dos professores, uma vez que este:

[...] tem regras e procedimentos que devem ser adquiridos e exercitados nas escolas de formação e nos primeiros anos de exercício docente. Sem isso, continuaremos a repetir intenções que dificilmente terão uma tradução concreta na vida dos professores e das escolas. (NÓVOA, 2009, p. 42).

Como última faceta na problemática da formação docente, ainda identificada no escrito de Nóvoa (2009), vem a questão pública, que reclama da formação um princípio de responsabilidade social que favoreça a comunicação e a participação profissional no espaço público educativo. O referido autor advoga que a ausência da voz dos professores nos debates públicos coopera para enfraquecer sua identidade e o reconhecimento do seu trabalho perante a sociedade.

Essas proposições de Nóvoa (2009) contribuem para fortalecer o entendimento de que o processo de desenvolvimento profissional docente não pode ser visto como mera replicação de teorias ou mesmo como aplicação de práticas alheias ao contexto (social/histórico/ cultural/econômico) dos professores. Isso implica a consciência de conceber a formação e o desenvolvimento profissional docente como responsabilidade coletiva dessa categoria profissional, requerendo uma atenção constante, não só dos professores, mas, em especial, das políticas públicas, para a necessidade de mudanças nas condições objetivas de trabalho desses sujeitos. Verifica-se, no entanto, que isso não é tarefa fácil, uma vez que exige esforços contínuos de reelaboração dos professores sobre suas concepções acerca do seu papel social e do que, de fato, vem a ser a formação e o desenvolvimento profissional, bem como de qual seja a relação de ambos os conceitos para o fortalecimento da profissão docente.

Entende-se que a profissão docente deve ser edificada tendo como alicerce um conjunto de fatores, tais como a aprendizagem ao longo da vida, o fortalecimento da identidade profissional, tendo como pano de fundo a participação dos professores nas grandes decisões dos organismos que ditam as políticas públicas, a valorização das relações sociais para além dos muros da escola/da universidade e o diálogo entre ambas. Sendo assim, é preciso que se reconheça o fato de que a formação não abarca todo o complexo do desenvolvimento profissional docente. 
Nessa direção, Nóvoa vem nos propor a “[...] teoria da pessoalidade no interior de uma teoria da profissionalidade" (NÓVOA, 2009, p. 39), ou seja, a organização de um conhecimento pessoal dentro do conhecimento profissional, no sentido de tecer uma profissão que ultrapasse a matriz científica ou mesmo pedagógica.

Associada à "teoria da pessoalidade" encontramos, ainda, em Nóvoa, a emergência de um professor atento às questões coletivas da profissão, considerando-se, porém, que "competência colectiva vai além do mero somatório das competências individuais" (NÓVOA, 2009, p. 40).

No que concerne à formação docente, é inegável que, quanto mais se fala da necessidade de autonomia dos professores, tanto mais se controla a sua atuação por instâncias distintas, o que acarreta redução das suas margens de liberdade e de independência. É por isso que, cada vez mais, urge a presença dos professores nas pequenas e nas grandes decisões relativas à sua profissão, de forma planejada e colaborativa.

No entanto, contrariando esse ideal, sabe-se que grande parte dos programas de formação contínua revela-se como projetos de grande inutilidade que, ao invés de subsidiarem o docente, acabam por complicarem mais o seu dia a dia.

Conforme Nóvoa (2007), deve-se contrariar a concepção da Educação Permanente, com a construção de dispositivos de formação a partir das necessidades das pessoas e da profissão, investindo na construção de redes de trabalho coletivo que sejam o suporte de práticas de formação baseadas na partilha e no diálogo profissional.

Efetivamente não é possível escrever textos atrás de textos sobre a práxis e o practicum, como referências do saber docente acerca dos professores reflexivos, se não concretizarmos uma maior presença da profissão na formação. O importante, então, é assegurar que a complexidade e a beleza do ensino possam vir a adquirir a mesma visibilidade de outros campos profissionais. E, ao mesmo tempo, é essencial reforçar dispositivos e práticas de formação de professores baseados na investigação (NÓVOA, 2007).

Por tais questionamentos, é que se defende mais e mais a ideia de que muitos programas de formação contínua estabelecem bem menos resultados do que, de fato, o que o nome lhes sugere, sobretudo, no que diz respeito à necessidade de contemplarem uma formação crítico-reflexiva do professor pautada em elementos teórico-práticos voltados para a constituição de uma práxis pedagógica com vistas a uma educação emancipatória.

\section{Considerações finais}

A frequência com que se depara com a temática "professor reflexivo", no âmbito dos debates docentes, aponta para a sua importância nos espaços de formação, muito embora algumas compreensões a respeito de tal temática aconteçam de forma um tanto enviesada, descontextualizada das reais condições objetivas as quais os professores levam a cabo sua profissão.

É pertinente mencionar que as propostas que creditam aos professores seu legítimo lugar de protagonistas em sua formação, partem da ideia que defende tal processo formativo a partir do pensamento reflexivo, algo que evidencia a necessidade de o professor pensar e repensar sua prática fugindo aos padrões preestabelecidos para o modelo ainda vigente da formação calcada em um cariz de racionalidade técnica, a bem da autonomia do profissional docente em seu trabalho pedagógico.

De tal modo, urge o desafio de se viabilizar processos de formação inicial e contínua que promovam efetivamente o desenvolvimento de educadores voltados à reflexão na atual realidade docente com vistas a uma mudança de paradigma no que concerne aos projetos voltados para a formação de professores, algo que deve ser mobilizado também, e principalmente, pela classe docente. 
Nesta discussão, que pôs em xeque os modelos de formação docente estabelecidos sob a égide da racionalidade técnica, ratifica-se a defesa da reflexão crítica como âncora que permita aos professores analisar e questionar as estruturas que regulam seu trabalho e sua formação. Acredita-se, ainda, que a compreensão do conceito de desenvolvimento profissional (que não nega a importância da formação, mas não se limita a esta), possibilitará aos professores maior autonomia para a retomada do estatuto da profissão docente.

Crê-se, enfim, que o desafio de viabilizar processos de formação inicial e contínua que promovam, de forma exitosa o desenvolvimento de educadores reflexivos, mais capazes de lidar com as mudanças e as incertezas do tempo presente, requer ordenamentos políticos, econômicos e pedagógicos que assegurem o desenvolvimento de uma nova cultura docente.

\section{Referências}

CONTRERAS, José. Autonomia de professores. 2. ed. São Paulo: Cortez, 2012.

DEWEY, Jonh. Como pensamos - como se relaciona o pensamento reflexivo com o processo educativo: uma reexposição. Tradução Haydée de Camargo Campos. 3. ed. São Paulo: Nacional, 1959.

FREIRE, Paulo. Educação e mudança. 12. ed. Rio de Janeiro: Paz e Terra, 1979. 2011.

Pedagogia da autonomia: saberes necessários à prática educativa. São Paulo: Paz e Terra,

GARCIA, Carlos Marcelo. Formação de professores: para uma mudança educativa. Porto: Porto Editora, 1999.

. A formação de Professores: centro de atenção e pedra-de-toque. In: NÓVOA, António (Org.): Os professores e a sua formação. Lisboa: Dom Quixote Editora, 2007, p. 51-76.

IMBERNÓN, Francesc. El desarrollo professional del professorado de primaria. XXI: Revista de Educación, Huelva, v. 1, p. 59-68, 1999.

NÓVOA, António. O regresso dos professores. In: CONFERÊNCIA DESENVOLVIMENTO PROFISSIONAL DE PROFESSORES PARA A QUALIDADE E PARA A EQUIDADE DA APRENDIZAGEM AO LONGO DA VIDA, 2007, Lisboa. Conferência Desenvolvimento profissional de professores para a qualidade e para a equidade da Aprendizagem ao longo da Vida. Lisboa: Ministério da Educação, 2007. p. 21-28. Disponível em: <https://escoladosargacal.files.wordpress.com/2009/05/ regressodosprofessoresantonionovoa.pdf $>$. Acesso em: 10 abr. 2016.

Professores, imagens do futuro presente. Lisboa: EDUCA, 2009.

SCHÖN, Donald. Educando o profissional reflexivo. Porto Alegre: Artes Médicas Sul, 2000. 
